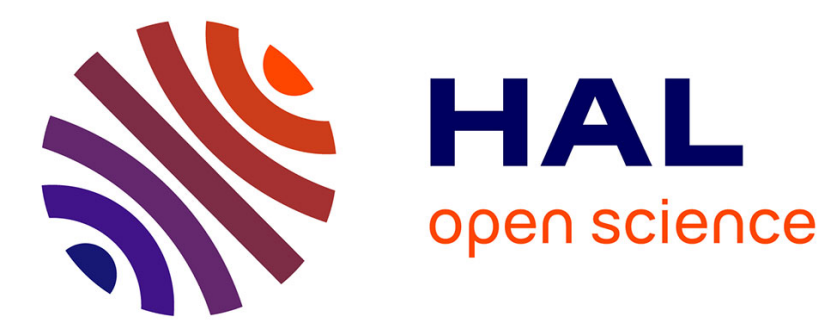

\title{
A new genus and species of phytoseiid mites (Acari: Mesostigmata) from the Brazilian Atlantic forest
}

\author{
Serge S. Kreiter, Marie-Stéphane M.-S. Tixier
}

\section{To cite this version:}

Serge S. Kreiter, Marie-Stéphane M.-S. Tixier. A new genus and species of phytoseiid mites (Acari: Mesostigmata) from the Brazilian Atlantic forest. Acarologia, 2010, 50 (2), pp.197-205. 10.1051/acarologia/20101973 . hal-00979842

\section{HAL Id: hal-00979842 \\ https://hal.science/hal-00979842}

Submitted on 16 Apr 2014

HAL is a multi-disciplinary open access archive for the deposit and dissemination of scientific research documents, whether they are published or not. The documents may come from teaching and research institutions in France or abroad, or from public or private research centers.
L'archive ouverte pluridisciplinaire HAL, est destinée au dépôt et à la diffusion de documents scientifiques de niveau recherche, publiés ou non, émanant des établissements d'enseignement et de recherche français ou étrangers, des laboratoires publics ou privés. 


\title{
A NEW GENUS AND SPECIES OF PHYTOSEIID MITES (ACARI: MESOSTIGMATA) FROM THE BRAZILIAN ATLANTIC FOREST
}

\author{
Serge KREITER and Marie-Stéphane TIXIER
}

(Received 30 january 2010; accepted 30 April 2010; published online 30 June 2010)

Montpellier SupAgro, Unité Mixte de Recherche, Centre de Biologie et de Gestion des Populations INRA/IRD/CIRAD/SupAgro, Campus International de Baillarguet, CS 30016, 34988 Montferrier sur Lez cedex, France. kreiter@supagro.inra.fr

ABSTRACT - The phytoseiid mite Ragusaseius ferraguti n. gen., n. sp. is described from the primary Atlantic Forest Mata Atlantica in Brazil, based on specimens collected on Cyphomandra calycina Sendth (Solanaceae). This mite is unique in the following combination of characters: setae J3 and J4 present; dorsal setae medium to long, except for J5, and serrated; ventrianal shield anteriorly eroded, containing only JV2 and occasionally ZV2 in addition to circumanal setae.

KEYWORDS - Phytoseiidae; taxonomy; predatory mites; Ragusaseius ferraguti n. gen., n. sp.

\section{INTRODUCTION}

The Phytoseiidae contains most of the species currently used as biocontrol agents of mite pests (Kostiainen and Hoy, 1996; McMurtry and Croft, 1997). More than 2,000 phytoseiid species, grouped in 84 genera, are presently known (Chant and McMurtry, 2003a, b; Moraes et al., 2004; Chant and McMurtry, 2004a, b; Chant and McMurtry, 2005a, b, c; Chant and McMurtry, 2006a, b; Kreiter and Tixier, 2006; Chant and McMurtry, 2007). Still, new groups of phytoseiids are expected to be found in areas of the world not adequately explored. The Brazilian Atlantic Forest (Mata Atlantica as referred to in Brazil) is one of those areas; it was considered by Myers (1988) as one of the "biodiversity hotspots", i.e. areas in the world prioritized for conservation, with exceptional concentration of endemic species and undergoing exceptional loss of habitat. During an exporadic survey conducted in the region of Itatiaia, in the domain of the Atlantic Forest, a new genus and a new species, here in described, were discovered. Because of the morphological singular characteristics of these taxa, this finding may contribute to a better understanding of evolution and historical biogeography of this important family of mites. A description of these two taxa is provided in this paper.

\section{MATERIAL AND METHODS}

Specimens of the mite here described were found in uncultivated areas. The specimens were transferred to $70 \%$ ethanol and later mounted in Hoyer's medium for examination under phase and interferential contrasts microscope.

After determining that the specimens did not fit any of the known genera and species (Chant and McMurtry, 2007), a description was prepared, using the terminologies of Lindquist and Evans (1965), as 
adapted by Rowell et al. (1978), for the dorsal idiosomal setae; of Chant and Yoshida-Shaul (1991) for the ventral idiosomal setae; and of Athias-Henriot (1975) for the idiosomal adenotaxy. All measurements are given in micrometers $(\mu \mathrm{m})$.

\section{RESULTS}

\section{Ragusaseius Kreiter, genus novum}

\section{Type species Ragusaseius ferraguti $\mathbf{n}$. sp.}

Diagnosis - This genus belongs to the sub-family Amblyseiinae as setae $\mathrm{z} 3$ and s6 are absent. It is unique in the combination of the following characteristics: dorsal setae serrated, all medium to long except for J5, presence of both J3 and J4 on the dorsal shield in addition to j1, j3, j4, j5, j6, J2, J5, ventrianal shield anteriorly eroded, with only JV2 and occasionally ZV2 in addition to circumanal setae. Having the peritremal shield fused anteriorly with adult dorsal shield (Fig. 1A), more than 25 pairs of idiosomal setae present, a sternal shield without posterior projection, a deutosternal groove narrow $<5 \mu \mathrm{m}$ in width, without forward migration of preanal setae JV2 and ZV2, preanal setae on male usually arranged in a triangular pattern, setae S4 present, ratio seta s4:Z1 <3.0:1.0, setae s4, Z4 and Z5 not greatly longer than other setae, setae J2 present, Ge II and Ge III without macroseta, fixed digit of the chelicera with more than 6 teeth, Ragusaseius $\mathbf{n}$. gen. keys to the tribe Neoseiulini (Chant and McMurtry, 2007). Chant and Mc Murtry (2007) defined this tribe as follows: ratio seta s4:j6 $<3.0: 1.0$; chelicera of normal size and shape, with fixed digit usually having 5 or fewer teeth; posterior margin of sternal shield straight or concave; peritremal shield narrow; preanal setae of female arranged in a triangular pattern; dorsolateral setae approximately equal in length. Within the tribe Neoseiulini, Ragusaseius n. gen. resembles the genera Macrocaudus Moraes, McMurtry and Mineiro, Evansoseius Sheals, Rubuseius Ragusa and Chileseius Gonzalez and Schuster in having more than 5 teeth on cheliceral digit and setae J4 present. However, it differs from Chileseius because of the absence of setae $\mathrm{j} 6$ and $\mathrm{ZV} 3$ and presence of setae J3, from Evansoseius because of the absence of setae $\mathrm{r} 5$ and $\mathrm{J} 1$ and the presence of setae R1 and J3, and at last from Rubuseius because of the presence of setae J3 and absence of setae J1. The genus Macrocaudus is the most similar to $R a$ gusaseius $\mathbf{n}$. gen. because of the presence of both J3 and J4. However JV3 is absent in Ragusaseius $\mathbf{n}$. gen. whereas present in Macrocaudus. In conclusion, Ragusaseius differs from all these species in the following combination of characters: pre-anal setae not arranged triangular because ventrianal shield is reduced, setae J3 and J4 present and setae JV3 absent.

Because of all these singular characters, Ragusaseius ferraguti $\mathbf{n}$. gen. is erected as a new genus in the tribe Neoseiulini

Adult Female (Figures 1-2) - Dorsal idiosomal shield reticulated, more regularly in the anterior part (propodosoma) than in the posterior part (opisthosoma). With 21 pairs of serrated and medium to long dorsal setae which can be assigned to the following formula: $10 \mathrm{~A}: 11 \mathrm{C} / \mathrm{JV}-3$ : ZV; this formula is unique within the Phytoseiidae (Chant and Yoshida-Shaul, 1992; Chant and McMurtry, 2007): 9 pairs of setae in the $j-J$ series $(j 1, j 3, j 4, j 5$, $j 6, J 2, J 3, J 4, J 5), 6$ pairs of setae in the $z-Z$ series (z2, $\mathrm{z} 4, \mathrm{z} 5, \mathrm{Z1}, \mathrm{Z4}, \mathrm{Z5}), 4$ pairs of setae in the s-S series (s4, S2, S4, S5), and 2 pairs of setae in the r-R series $(\mathrm{r} 3, \mathrm{R} 1)$. The dorsal shield bears 4 pairs of solenostomes (gd1, gd2, gd6, gd9) and 16 pairs of poroids. Lines j3-gd1-z2 and $z 4-g d 2-z 4$ with angles $>$ than 180. Lines Z1-gd6-z5 and R1-gd6-j6 forming each almost an angle of $180^{\circ}$. Solenostome gd 9 very close to S5. Apex of peritremes extending to the level between j1 and j3. Sternal shield smooth. Anterior and posterior margins of the sternal shield convex and slightly concave, respectively. Five pairs of sternal setae (st1-st5; setae st4 on metasternal shield). Ventrianal shield vase-shaped, reticulated and anteriorly eroded, 7 pairs of caudoventral setae (JV1, JV2, JV4, JV5, ZV1, ZV2, ZV3); JV2 and occasionally $\mathrm{ZV} 2$ are the only pairs of setae inserted on the ventrianal shield (in addition to circumanal setae); setae JV3 absent; with one pair of solenostome, gv3. With two pairs of metapodal shields. Spermatheca with calyx pocular; atrium not distinct. Fixed cheliceral digit multidentate; movable digit with several large 


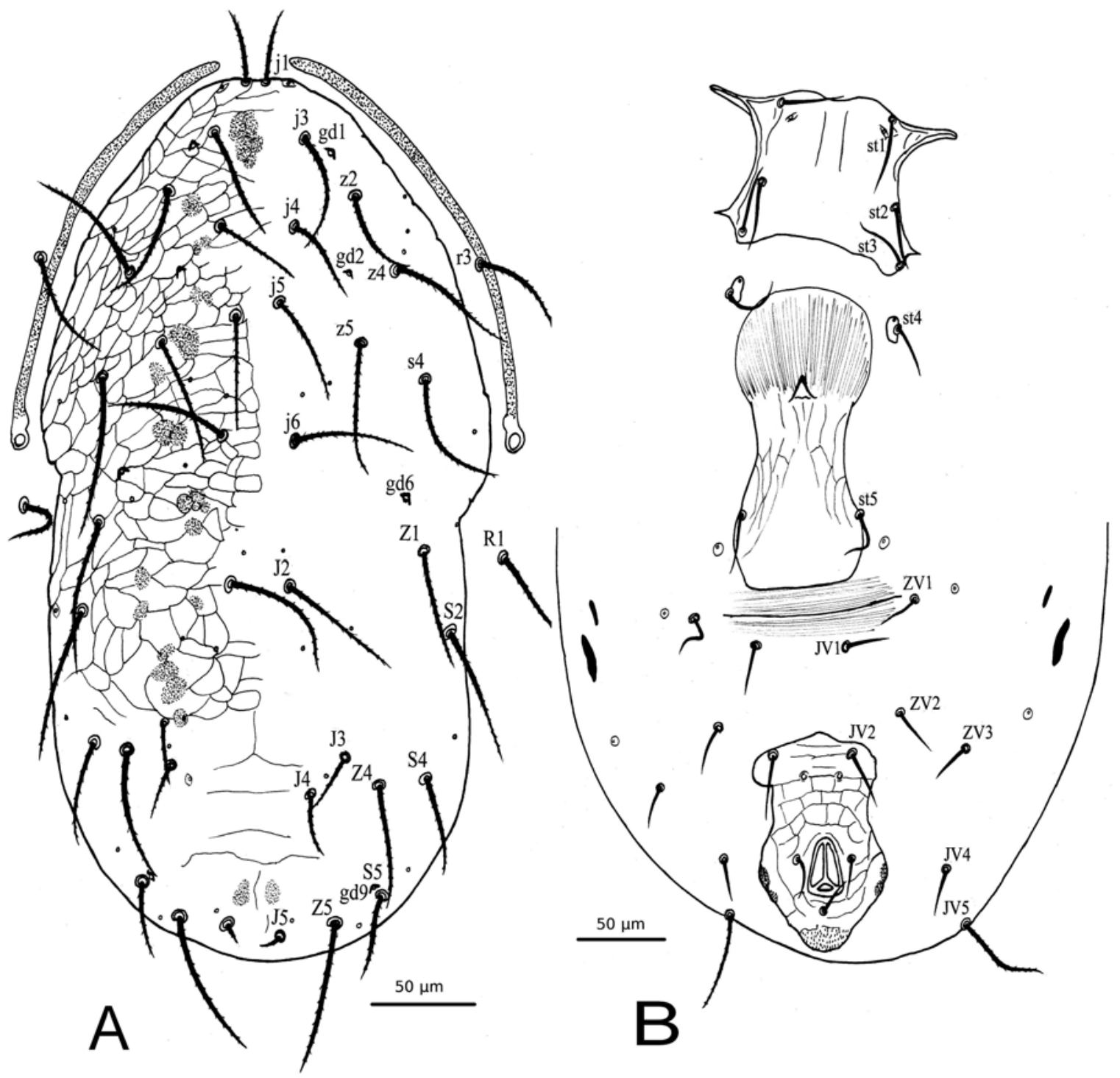

FIGURE 1: Ragusaseius ferraguti n. g., n. sp.. Female. (A) - Dorsal idiosoma; (B) - Ventral idiosoma; (C) - Variation in shape of the ventrianal shield.

teeth. No distinct macrosetae on the first 3 pairs of legs; leg IV with 3 slightly knobbed macrosetae.

Adult Male (Figure 3) - Reticulation of idiosomal shields and chaetotaxy similar to female. Anterior and posterior margins of sternogenital shield convex and straight, respectively. Seta JV5 on caudoventral cuticule; other caudoventral setae (JV1, JV2 and ZV2) on the sub-triangular ventrianal shield. Spermatodactyl L-shaped.
Etymology - The name of the genus refers to Professor Salvatore Ragusa di Chiara (University of Palermo, Italy), who has greatly contributed to the taxonomy and biology of the phytoseiids.

\section{Ragusaseius ferraguti Kreiter, n. sp.}

(Figures 1-3)

Diagnosis - This species can be distinguished 


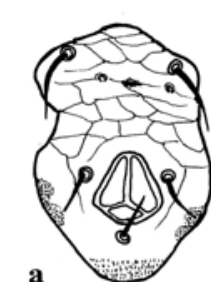

a
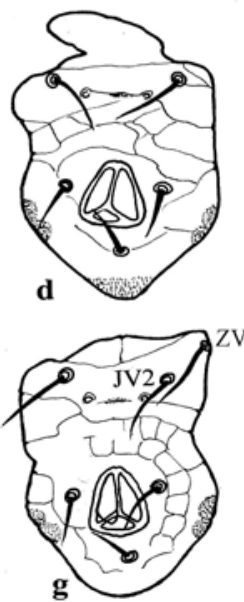
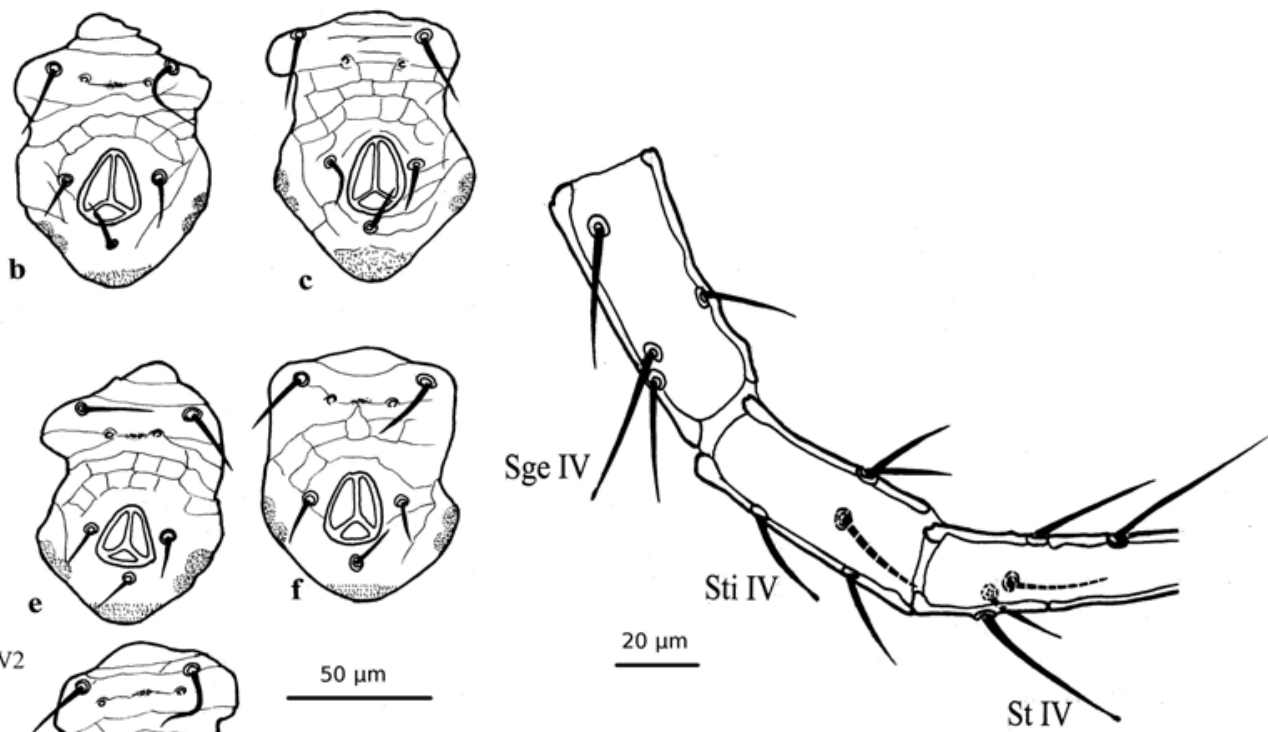

A

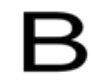

h
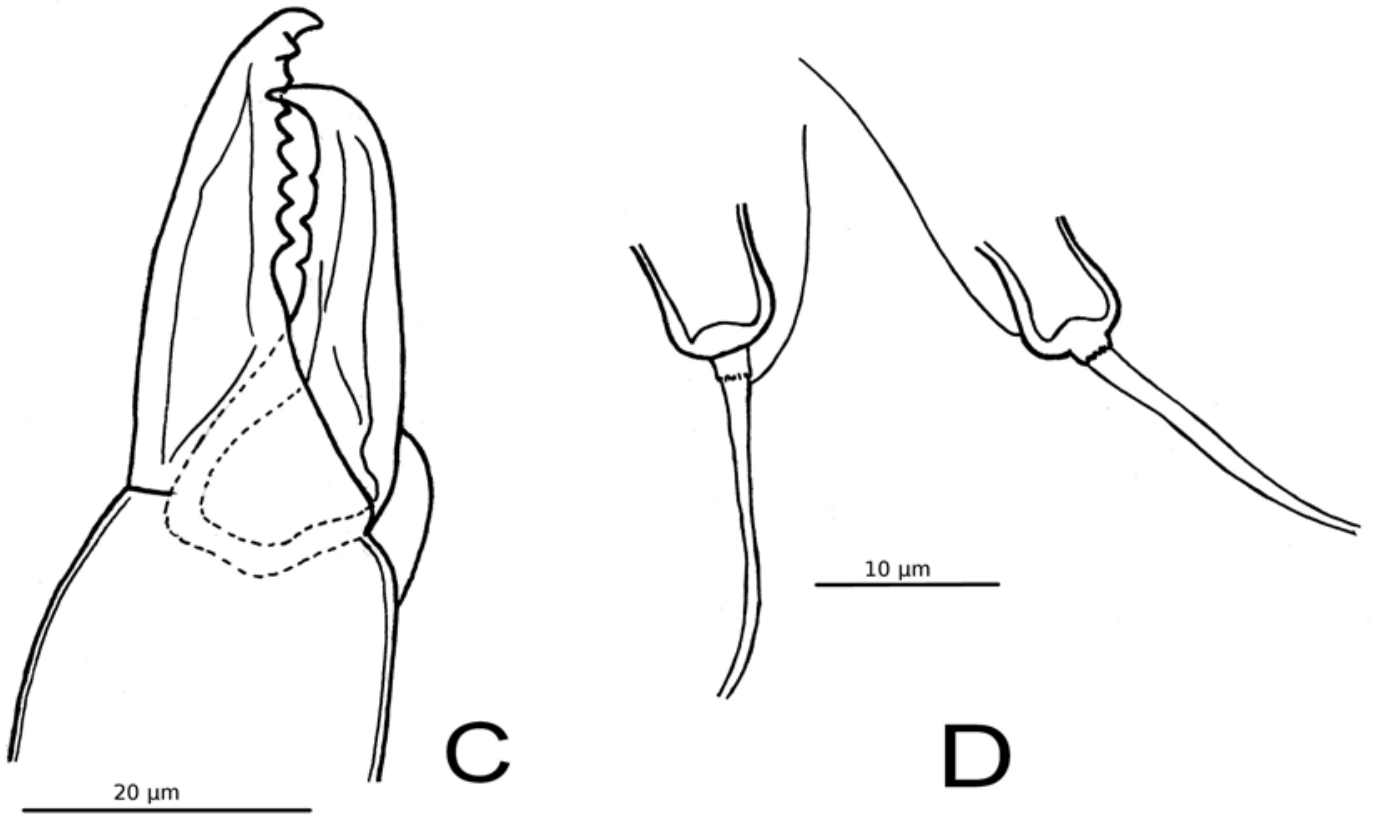

$\mathrm{D}$

FIGURE 2: Ragusaseius ferraguti n. g., n. sp.. Female. (A) - Variation in shape of the ventrianal shield. The most common are a, $b$ (female paratypes) and c (female holotype and several paratypes). Setae JV2 usually present. Only one specimen (g) with one member of setae ZV2 in addition to JV2; (B) - Leg IV; (C) - Chelicera; (D) - Spermatheca. 
from other phytoseiid species by the combination of characters given in the description below.

Adult Female (Figures 1-3) $(\mathrm{n}=51)$

Dorsum (Figure 1A) - Dorsal shield reticulated more regularly in the anterior part, 352 (328-400) long and 208 (198-220) wide, with 4 solenostomes (gd1, gd2, gd6 and gd9), 16 pairs of poroids, 19 pairs of dorsal shield setae and 2 pairs of sub-lateral setae, all medium to long and serrated: j1 29 (28-30), j3 50 (48-53), j4 43 (40-45), j5 50 (48-53), j6 60 (55-63), J2 61 (58-63), J3 30 (23-38), J4 26 (23-28), J5 12 (1013), z2 53 (48-58), z4 61 (55-68), z5 59 (53-70), Z1 59 (55-63), Z4 55 (50-58), Z5 67 (65-73), s4 72 (68-78), S2 61 (58-65), S4 38 (35-43), S5 33 (30-38), r3 48 (45-53), R1 37 (35-40). Seta J3 inserted between setae J4 and $\mathrm{Z} 4$, slightly closer to the former and not in line with $\mathrm{J} 2$ and J4. Setae r3 and R1 inserted on the lateral cuticle. Setae j3, z2, J3 and J4 sometimes absent in some adult females (out of the 52 females observed 7 without $\mathrm{J} 3$ on one side of the body, 2 without J3 on one side and $\mathrm{J} 4$ on the other side, 1 female without $\mathrm{J} 3$ on both sides, 1 female without $\mathrm{J} 4$ on both sides, 1 female without both $\mathrm{j} 1$ and both $\mathrm{j} 3$ and with only one $\mathrm{z} 2$ ).

Peritreme (Figure 1A) — Extending anteriorly almost to the level of $j 1$.

Venter (Figure 1B) - Sternal shield smooth, with 3 pairs of setae and 2 pairs of lyrifissures; st 4 on a small metasternal shield with one lyrifissure; posterior margin slightly concave. Distances between st1-st1 61 (60-63), st2-st2 71 (68-75), st3-st3 82 (80$88)$, st1-st3 67 (63-70), st4-st4 87 (75-95), st5-st5 65 (63-68). Two elongate metapodal shields, primary shield 16 (13-18) long and 2 wide and secondary shield 26 (23-28) long and 4 wide. Ventrianal shield reticulated, variously shaped, but usually vase-shaped (Fig. 2A a-h); 99 (90-103) long, 66 (58-70) wide at level of anterior corners and 66 (6070 ) wide at level of anus; with only 1 pair of preanal setae, JV2 and occasionally ZV2 are the only pairs of setae inserted on the ventrianal shield (in addition to circumanal setae), one pair of oblong preanal solenostome gv3 posteromesad to JV2. Membrane surrounding ventrianal shield with 6 pairs of setae (ZV1, ZV2, ZV3, JV1, JV4, JV5) and 3 pairs of pores; JV5 47 (43-53) long, serrated.
Legs (Figure 2B) - Leg IV with three slightly knobbed macrosetae: Sge IV 26 (23-28), Sti IV 25 (20-28), St IV 40 (38-43). No macrosetae on the other legs. Chaetotactic formula of genu II: 2-2/0, 2/1-1; genu III: 2-1/1, 2/0-0. Lengths of leg I: 409 (388425), leg II: 338 (308-363), leg III: 320 (288-350), leg IV: 450 (375-493).

Chelicera (Figure 2C) - Fixed digit 35 (33-38) long, with 7 large teeth; movable digit 37 (35-40) long, with 3 large teeth.

Spermatheca (Figure 2D) - Calyx pocular (Denmark et al., 1999), 9 (8-13) long and 8 wide at junction with vesicle; atrium indistinct.

\section{Adult Male (Figure 3) (n=7)}

Dorsum (Figure 3A) - Dorsal shield pattern similar to female, 293 (285-305) long and 196 (190-198) wide but solenostomes and poroids difficult to see in paratype males. Setae j1 23 (23-25), j3 36 (3538), j4 32 (30-33), j5 35 (33-38), j6 43, J2 41 (40-43), J3 27 (25-30), J4 24 (23-25), J5 12 (10-13), z2 38, z4 41 (38-45), z5 41 (35-43), Z1 42 (40-43), Z4 39 (3840), Z5 39 (38-40), s4 55, S2 43, S4 33, S5 29 (28-33), r3 35 (33-38), R1 29 (28-30). Setae J3 inserted between J4 and Z4, slightly closer to the former and not strictly in line with J2 and J4. Setae r3 and R1 inserted on the lateral cuticle. No variation in the presence/absence of setae of the dorsal shield in the 7 paratype males collected and examined.

Peritreme (Figure 3A) - Extending anteriorly to the level between $\mathrm{j} 1$ and $\mathrm{j} 3$.

Venter (Figure 3B) - Sternogenital shield smooth, with 5 pairs of setae and 3 pairs of lyrifissures. Distances between st1-st1 57 (55-63), st2st2 63, st3-st3 63, st4-st4 54 (53-55), st5-st5 45 (4348), st1-st5 123 (120-128). Ventrianal shield subtriangular and reticulated, 123 (120-125) long, 162 (153-168) wide at level of anterior corners and 72 (68-75) at level of anus; eroded, with 3 pairs of preanal setae (JV1, JV2 and ZV2), one pair of pre-anal solenostomes gv3 and 5 pairs of poroids; ventrianal shield not fused with the peritremal shields. Membrane surrounding the ventrianal shield with only one pair of setae (JV5) and no pore; JV5 30 (28-30) long, serrated. 
Legs - Macrosetae on leg IV similar to the same in female: Sge IV 23 (21-25), Sti IV 22 (20-23), St IV 33 (30-35). No macrosetae on the other legs. Chaetotactic formula of genua II and III as in female. Lengths of leg I: 349 (338-375), II: 298 (288313), III: 293 (275-325), IV: 406 (375-438).

Chelicera (Figure 3C) - Spermatodactyl Lshaped; shaft 15 long, toe 11 (10-12). Teeth on movable and fixed digits not visible.

Type material: Holotype female, 26 paratype females and two paratype males (on 5 preparations with 6 females, 10 females and 1 male, 4 females, 1 female and 1 male, and 6 females, respectively) collected by S. Kreiter from Cyphomandra calycina Sendth (Solanaceae) at a place located $1 \mathrm{~km}$ from the Center of the City of Itatiaia, State of Rio de Janeiro

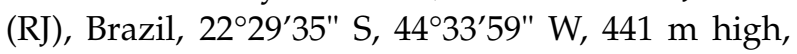
October 1998, deposited in USP/ ESALQ, Departamento de Fitopatologia, Entomologia and Zoologia agricola, laboratory of Acarology collection, Piracicaba, SP, Brazil. Twenty-four paratype females (on 4 preparations) and 5 paratype males (on 1 preparation) collected by S. Kreiter from Cyphomandra calycina Sendth (Solanaceae) at a place located 1 from the Center of the City of Itatiaia, State of Rio de

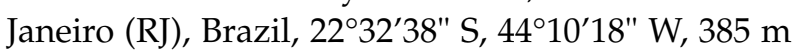
high, 10 October 1998, deposited in the SupAgro INRA Acarology collection, Montpellier, France.

Etymology: This species is named after Professor Francisco Ferragut (Universita Politecnica de Valencia, Spain), who has greatly contributed to the taxonomy and biology of the phytoseiids.

\section{DISCUSSION}

As seta J3 is not exactly aligned with the axis J2-J5 (and at least with setae J2 and J4), this seta could be interpreted as J3 or as Z3. We choose the first hypothesis for the following reasons:

(1) The unalignment of setae J3 on the j-J's line might be due to a slide mounting 's artefact. A small protuberance in live specimens between $\mathrm{J} 2$ and $\mathrm{J} 4$ seems to exist (not seen in alive specimens because collected and put in vials, without possibility of observations but a kind of protuberance is observed in some preparations), then after slide mounting, this protuberance could have been flattened conducing to the migration of setae $\mathrm{J} 3$ towards $\mathrm{Z} 4$.

(2) If slide mounting's artefact does not exist, another explanation could be that the existence of this protuberance itself might have already modified this alignment on live specimens. This is for instance the case of the setae $j 3$, that do not aligned with the axis j1-j6 (Chant and McMurtry, 2007).

(3) This seta is also not aligned with Z1-Z4. If this seta was in the normal Z3 position, as in M. multisetatus, the dorsal shield might have been slightly constricted mediolaterally, as in this latter species, which might have also affected the positions of setae S2 and S4, which is not the case.

The absence of J3 was one of the character states used to distinguish phytoseiids from mites of other families of Mesostigmata, until M. multisetatus was described (Moraes et al., 2003). Ragusaseius ferraguti n. gen., n. sp. and M. multisetatus are thus two unique phytoseiid species in bearing seta J3. Macrocaudus multisetatus has not only $\mathrm{J} 3$ present but also J4 and Z3, three setae usually absent in the family Phytoseiidae. As this latter species, Ragusaseius ferraguti n. gen., n. sp. also has J4. Only five species in addition to M. multisetatus have setae J4, all belonging to the sub-family Amblyseiinae: Evansoseius macfarlenei Sheals, Rubuseius aristoteliae Ragusa and Chileseius camposi Gonzalez and Schuster in the tribe Neoseiulini, Typhloseiella perforata (Wainstein) in the tribe Kampimodromini, and Pararrenoseius mumai (Prasad) in the tribe Amblyseiini. However, contrarily to Ragusaseius ferraguti n. gen., n. sp., E. macfarlenei and $R$. aristoteliae also have J1, C. camposi $\mathrm{Z} 3$ and $\mathrm{z} 6$, and T. perforata $\mathrm{Z} 2$.

Because of some characters considered as plesiomorphies, i.e. the large number of idiosomal setae, the absence of setae $\mathrm{z} 3$ and $\mathrm{s} 6$, the absence of JV3 and the presence of J3 and J4, Ragusaseius ferraguti n. gen., n. sp. could be assumed an early derivative species of Amblyseiinae, as it was also suggested for M. multisetatus and C. camposi (Moraes et al., 2003; Chant and McMurtry, 2007). Furthermore, these features are rare among Phytoseiid, the genera close to Ragusaseius ferraguti $\mathbf{n}$. gen., n. sp. are usually monotypic and species collected a few times. Rarety could be due to ex- 

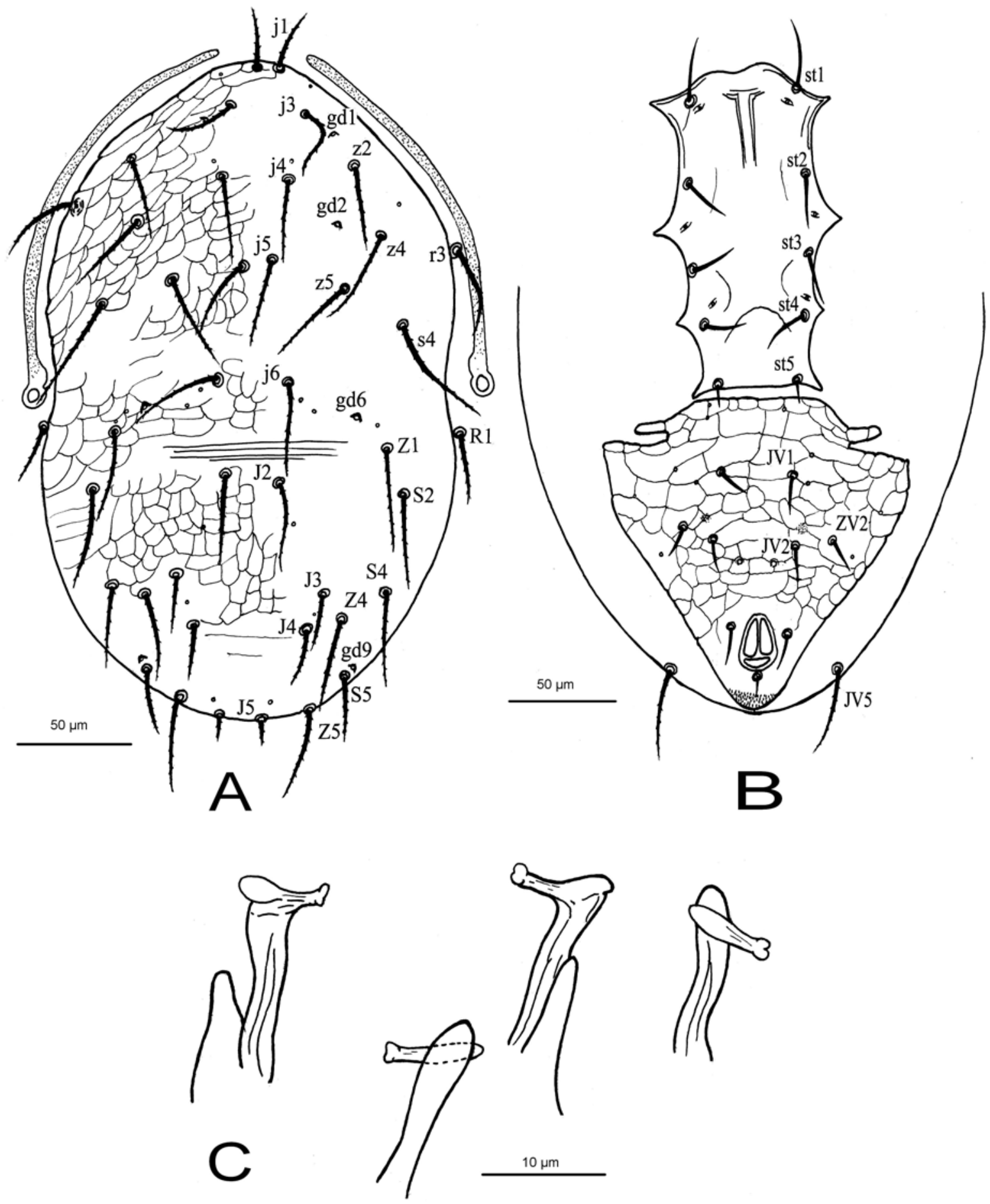

FIGURE 3: Ragusaseius ferraguti n. g., n. sp.. Male; (A) - Dorsal idiosoma; (B) - Ventral idiosoma; (C) - Spermatodactyl. 
tinction process or to habitat specialisation. Except for P. mumai which was collected in Hawaï, all the other species having J3 and/or J4 were reported from South America (Neotropical region), which probably support the hypothetical Gondwanian origin of Amblyseiinae suggested by Tixier et al. (2008). However, confirmation of this will require phylogenetic analyses combined with historical biogeography approaches. Furthermore, the plants that housed Ragusaseius, Macrocaudus, Evansoseius, Rubuseius ands Chileseius may also reveal interesting information in support of this hypothesis.

Ragusaseius ferraguti n. gen., n. sp. was collected on a solanaceous shrub, Cyphomandra calycina Sendth, whereas M. multisetatus and E. macfarlanei were collected on floating aquatic ferns of the genera Salvinia and Azolla, respectively. The other species having J4 were also collected on various terrestrial plants: C. camposi was collected on vines, and $R$. aristoteliae on Rubus ulmifolius Schott (Rosaceae), Aristotelia chilensis (Molina) Stuntz (Elaeocarpaceae) and Aextoxicon punctatum Ruiz and Pavón (Aetoxicaceae). More surveys in remote areas of the South Americas may reveal additional interesting species and support for their singularity.

\section{ACKNOWLEDGEMENTS}

The survey leading to the discovery of this new genus and new species was done within the scope of a cooperation between COFECUB (Comité Français de Coopération Universitaire avec le Brésil) and University of Sao Paulo (project nr. UC 41 / 97). We are grateful to all people that have helped the organisation of this survey. Authors are very grateful to Gilberto J. de Moraes and Bruce Halliday for very valuable comments on early versions of this manuscript.

\section{REFERENCES}

Athias-Henriot C. 1975 - Nouvelles notes sur les Amblyseiini. II. Le relevé organotaxique de la face dorsale adulte (Gamasides protoadéniques, Phytoseiidae) Acarologia, 17: 20-29.
Chant D.A. and McMurtry J.A. 2003a - A review of the subfamilies Amblyseiinae: Part II. Neoseiulini new tribe - International Journal of Acarology, 29: 3-46.

Chant D.A. and McMurtry J.A. 2003b - A review of the subfamilies Amblyseiinae (Acari: Phytoseiidae): Part II. The tribe Kampimodromini - International Journal of Acarology, 29: 179-224.

Chant D.A. and McMurtry J.A. 2004a - A review of the subfamily Amblyseiinae Muma (Acari: Phytoseiidae) Part III. The tribe Amblyseiini Wainstein, subtribe Amblyseiina N. subtribe - International Journal of Acarology, 30: 171-228.

Chant D.A. and McMurtry J.A. 2004b - A review of the subfamily Amblyseiinae Muma (Acari: Phytoseiidae) Part IV. The tribe Amblyseiini Wainstein, subtrive Arrenoseiina Chant and McMurtry - International Journal of Acarology, 30: 291-312.

Chant D.A. and McMurtry J.A. 2005a - A review of the subfamily Amblyseiinae Muma (Acari: Phytoseiidae) Part V. Tribe Amblyseiini, subtribe Proprioseiopsina Chant and McMurtry - International Journal of Acarology, 31: 3-22.

Chant D.A. and McMurtry J.A. 2005b - A review of the subfamily Amblyseiinae Muma (Acari: Phytoseiidae) Part VI. The tribe Euseiini N. tribe, subtribes Typhlodromalina, N. subtribe, Euseiina N. subtribe and Ricoseiina N. subtribe - International Journal of Acarology, 31: 187-224.

Chant D.A. and McMurtry J.A. 2005c - A review of the subfamily Amblyseiinae Muma (Acari: Phytoseiidae) Part VII. Typhlodromipsini n. tribe - International Journal of Acarology, 31: 315-340.

Chant D.A. and McMurtry J.A. 2006a - A review of the subfamily Amblyseiinae Muma (Acari: Phytoseiidae) Part VIII. The tribes Macroseiini Chant, Denmark and Baker, Phytoseiulini n. tribe, Africoseiulini n. tribe and Indoseiulini Ehara and Amano - International Journal of Acarology, 32: 13-25.

Chant D.A. and McMurtry J.A. (2006b - A review of the subfamily Amblyseiinae Muma (Acari: Phytoseiidae) Part IX. An overview - International Journal of Acarology, 32: 125-152.

Chant D.A. and McMurtry J.A. 2007 - Illustrated keys and diagnoses for the genera and sub-genera of the Phytoseiidae of the World - Indira Publishing House, West Bloomfield, Michigan, pp. 220.

Chant D. A. and Yoshida Shaul E. 1991 - Adult ventral setal patterns in the family Phytoseiidae (Acari: Gamasina) - International Journal of Acarology, 17: 187-199.

Chant D. A. and Yoshida Shaul E. 1992 - Adult idiosomal setal patterns in the family Phytoseiidae (Acari: 
Gamasina) - International Journal of Acarology, 18: 177-193.

Denmark H.A., Evans G.A., Aguilar H., Vargas C. and Ochoa R. 1999 - Phytoseiidae of Central America (Acari: Mesostigmata) - Indira Publishing House, West Bloomfield, Michigan, pp. 125.

Kostiainen T.S. and Hoy M.A. 1996 - The Phytoseiidae as biological control agents of pest mites and insects. A bibliography - Monograph 17, University of Florida, Agricultural Experiment Station, Florida, pp. 355.

Kreiter S. and Tixier M.-S. 2006 - A new genus and a new species of Phytoseiid mites (Acari: Mesostigmata) from Southern Tunisia with analysis and discussion on its phylogenetic position - Zootaxa, 1237: 1-18.

Lindquist E.E. and Evans G.W. 1965 - Taxonomic concepts in the Ascidae, with a modified setal nomenclature for the idiosoma of the Gamasina (Acarina: Mesostigmata) - Memoirs of the Entomological Society of Canada, 47: 1-64.

McMurtry J. A. and Croft B. A. 1997 — Life-styles of phytoseiid mites and their roles in biological control Annual Review Entomology, 42: 291-321.

Moraes G.J. de, McMurtry J.A. and de Carvalho Mineiro J.L. 2003 - A new genus and species of phytoseiid mites (Acari: Phytoseiidae) from Brazil - International Journal of Acarology, 29: 47-54.

Moraes G.J. de, McMurtry J.A., Denmark H.A. and Campos C.B. 2004 - A revised catalog of the mite family Phytoseiidae - Zootaxa, 434: 1-494.

Myers N. 1988 - Threatened biotas: hostspots in tropical forests - Environmentalist, 8: 187-208.

Rowell H. J., Chant D. A. and Hansell R.I.C. 1978 - The determination of setal homologies and setal patterns of the dorsal shield in the family Phytoseiidae (Acarina: Mesostigmata) - The Canadian Entomologist, 110: 859-876.

Tixier M.-S., Kreiter S. and Moraes G.J. 2008 - Biogeographic distribution of the mites of the family Phytoseiidae (Acari: Mesostigmata) - Biological Journal of the Linnean Society, 93: 845-856.

\section{COPYRIGHT}

$((c)$ EY-NC-ND Kreiter and Tixier. Acarologia is under free license. This open-access article is distributed under the terms of the Creative Commons-BY-NC-ND which permits unrestricted non-commercial use, distribution, and reproduction in any medium, provided the original author and source are credited. 